\title{
Oviduct cyst observed together with a uterine serosal inclusion cyst in the Anatolian water buffalo - a case report
}

\author{
Alper Sevimli ${ }^{1}$, Erhan Ozenc ${ }^{2}$, Duygu Baki Acar ${ }^{2}$ \\ ${ }^{1}$ Afyon Kocatepe University, Faculty of Veterinary Medicine, Department of Pathology, Afyonkarahisar, Turkey \\ ${ }^{2}$ Afyon Kocatepe University, Faculty of Veterinary Medicine, Department of Obstetrics and Gynaecology, \\ Afyonkarahisar, Turkey \\ Received October 13, 2011 \\ Accepted July 16, 2012
}

\begin{abstract}
The aim of this study was to report the oviduct cyst together with uterine serosal inclusion cysts observed in a 5-year-old female Anatolian water buffalo (Bubalus bubalis). General examination of the animal before slaughtering revealed no health problems. Blood was collected from jugular vein and serum was separated. Serum estradiol and progesterone concentrations were determined using electrochemiluminescence immunoassay. Uterine and oviduct samples were obtained from the buffalo after slaughter. These samples were processed routinely and stained with haematoxylin and eosin stain for histopathological examination. A corpus albicans together with a follicle in a diameter of $1.6 \mathrm{~cm}$, located on the left ovary was detected during ultrasonographic examination performed in a water bath of the genital organs after slaughter. Serum oestrogen and progesterone concentrations were determined as $23 \mathrm{pg} / \mathrm{ml}$ and $0.53 \mathrm{ng} / \mathrm{ml}$, respectively. Cysts demonstrating multifocal serosal form of location in uterine horns were seen. Cysts similar to the uterine cysts were seen also in the oviduct. Cystic structures in a diameter ranging from $0.3 \mathrm{~cm}$ to $1 \mathrm{~cm}$ were observed in uterine horns, whereas cystic formations in a diameter ranging from $0.5 \mathrm{~cm}$ to $0.7 \mathrm{~cm}$ were seen in the mesosalpinx of the right and left oviducts. The cysts were surrounded by epithelium differing from a single layer of flat epithelium to cubic epithelium. This is the first study describing the oviduct cyst observed together with uterine serosal inclusion cysts in Anatolian water buffalo.
\end{abstract}

Bubalus bubalis, genital tract, reproduction

Serosal inclusion cysts are structures developing mesotelium due to rapid uterine contractions during involution of the uterus in the postpartum period (McEntee 1990). The high level of oestrogen in the oestrous cycle may act as a causative factor by increasing contractions of the uterus (Vural et al. 2004). These cysts do not appear to have any effect on fertility but cyst formation may be associated with hormonal dysfunction (Schlafer and Miller 2007). Serosal inclusion cysts are observed either in solitary or multifocal form frequently during ovariohysterectomy in dogs (Kennedy and Miller 1993; Vural et al. 2004; Schlafer and Gifford 2008) and cats (Godfrey and Silkstone 1998) and are found coincidentally in water buffaloes during slaughter at slaughterhouses (Saxena et al. 2006).

The aim of our study was to report the oviduct cyst observed together with uterine serosal inclusion cysts in an Anatolian water buffalo.

\section{Case report}

A five-year-old female Anatolian water buffalo was sent to the slaughterhouse. General examination before slaughtering revealed no health problems. Blood was collected from jugular vein and serum was separated by centrifugation and stored at $-20{ }^{\circ} \mathrm{C}$ until used for biochemical analysis. The serum oestradiol and progesterone concentrations were determined using an electrochemiluminescence immunoassay (ECLIA) with a modular analytics analyzer (Roche E170; Roche Diagnostics GmbH, Mannheim, Germany). The

Address for correspondence:

Dr. Erhan Ozenc

Department of Obstetrics and Gynaecology

Faculty of Veterinary Medicine, Afyon Kocatepe University

03200, Afyonkarahisar, Turkey 
serum oestradiol and progesterone levels were $23 \mathrm{pg} / \mathrm{ml}$ and $0.53 \mathrm{ng} / \mathrm{ml}$, respectively. Following slaughter, no abnormalities were found on the screening of the surfaces of the other thoracic and abdominal organs in postmortal examination. Morphological structures on each ovary and uterus were first examined externally and then in a water bath using and ultrasound device (100 Falco Vet, Pie Medical Equipment BV, Philipsweg 1, 6227 Aj, Netherlands). Multiple formation of fluctuant cystic structures in a diameter ranging from $0.3 \mathrm{~cm}$ to $1 \mathrm{~cm}$ were observed in the uterine horns. Cystic formations in similar structures in a diameter ranging from $0.5 \mathrm{~cm}$ to $0.7 \mathrm{~cm}$ were seen in the mesosalpinx of the right and left oviducts (Plate I, Fig. 1). The size of the right ovary was $2.3 \mathrm{~cm} \times 1.2 \mathrm{~cm}$ and the left ovary was $2.7 \mathrm{~cm} \times 1.5 \mathrm{~cm}$ in diameter. Corpus albicans together with a follicle of $1.6 \mathrm{~cm}$ in diameter, located on the left ovary was detected during ultrasonographic examination performed in a water bath of the genital organs.

Uterine and oviduct samples were fixed in $10 \%$ phosphate-buffered formaldehyde solution for $24 \mathrm{~h}$ and processed to paraffin, sectioned at $5 \mu \mathrm{m}$ and stained with haematoxylin and eosin stain for histopathological examination (Lee and Luna 1968). Cysts surrounded by epithelium differing from a single layer of flat epithelium to cubic epithelium were observed at the serosa of the right and left uterine horn. Some of the cysts were empty inside; however, some of them were enclosed by homogeneous, vacuolar and amorphous structures pink in colour (Plate I, Fig. 2). No myometrial, endometrial and ovarian lesions were found in the uterus. Cysts similar to the uterine cysts were seen also in the oviduct (Plate II, Fig. 3).

\section{Discussion}

The female genital tract of buffaloes is known to have biological and economic importance. Although there have been numerous slaughterhouse studies on the genital system of buffaloes (Sujata 2000; Tafti and Darahshiri 2000; Saxena et al. 2006), there have been no studies reporting serosal inclusion cyst together with oviduct cysts yet. Tsumura et al. (1982) reported that cyst formation in the oviduct was most frequently seen in the fimbriae in cows and in the mesosalpinx in sows. The diameters of these cysts were generally found to be less than $5.9 \mathrm{~mm}$. In our study, bilateral cyst formation with $0.5-0.7 \mathrm{~cm}$ in diameter, was seen in mesosalpinx of the water buffalo. Tsumura et al. (1982) reported that sex hormones and oviductal constrictions might cause oviduct cysts. In our study, serum oestradiol concentration was $23 \mathrm{pg} / \mathrm{ml}$ and serum progesterone concentration was $0.53 \mathrm{ng} / \mathrm{ml}$. The measured oestradiol and progesterone levels were determined to be consistent with the mean total oestrogen peak concentration of $23.9 \pm 3.9 \mathrm{pg} / \mathrm{ml}$ (Mohan et al. 2010) and the mean progesterone concentration of $0.3 \pm 0.1 \mathrm{ng} / \mathrm{ml}$ (Mondal et al. 2010), observed during the oestrous phase of the sexual cycle in water buffaloes. Corpus albicans observed on the left ovary demonstrates reduction in the concentration of serum progesterone. Our findings may be due to the high level of oestrogen found in the oestrous phase of animals. This phase of sexual cycle that increases the contractions of the uterus may be a causative factor in the serosal inclusion cysts.

Based on the results of our study, we can conclude that depending on the value of high oestrogen in buffaloes, uterine serosal inclusion cysts can be observed together with the oviduct cyst.

\section{References}

Godfrey DR, Silkstone MA 1998: Uterine serosal inclusion cysts in a cat. Vet Rec 142: 673

Kennedy PC, Miller RB 1993: The female genital system. In: Jubb KVF, Kennedy PC, Palmer AC (Eds.): Pathology of domestic animals. Academic Press, London, pp. 349-470

Lee G, Luna HT 1968: Manual of histologic staining methods of the Armed Forces Institute of Pathology. $3^{\text {rd }}$ edition. Mc Graw Hill Book Company, New York, pp. 235-236. 
McEntee K 1990: The uterus: degenerative and inflammatory lesions. In: McEntee K (Ed.): Reproductive pathology of domestic animals. Academic Press, New York, pp. 158-159

Mohan K, Kumar V, Sarkar M, Prakash BS 2010: Temporal changes in endogenous estrogens and expression of behaviors associated with estrus during the periovulatory period in Murah buffaloes (Bubalus bubalis). Trop Anim Health Prod 42: 21-26

Mondal S, Suresh KP, Nandi S 2010: Endocrine profiles of oestrous cycle in buffalo: A meta-analysis. Asian-Aust J Anim Sci 23: 169-174

Saxena G, Rani S, Danodia HK, Purohit GN 2006: Pathological conditions in genital tract of female buffaloes (Bubalus bubalis). Pakistan Vet J 26: 91-93

Schlafer DH, Miller RB 2007: Female genital system. In: Maxie M (Eds.): Jubb, Kennedy, and Palmer's pathology of domestic animals. Elsevier Limited, China, pp. 429-564

Schlafer DH, Gifford AT 2008: Cystic endometrial hyperplasia, pseudo-placentational endometrial hyperplasia, and other cystic conditions of the canine and feline uterus. Theriogenology 70: 349-358

Sujata S 2000: Pathology of reproductive organs in buffaloes of North Karnataka region. Indian J Vet Pathol 24: 150

Tafti A, Darahshiri MR 2000: Studies on the uterine abnormalities of slaughtered non- pregnant adult cows. Indian Vet J 77: 1059-1062

Tsumura I, Sasaki H, Minami S, Nonami K, Nakaniwa S 1982: Cyst formation in mesosalpinx, mesovarium and fimbria in cows and sows. Jpn J Vet Sci 44: 1-8

Vural SA, Haligur M, Ozenc E 2004: Uterine serosal inclusion cysts in dogs: Pathomorphological and immunohistochemical findings (in German). Kleintierpraxis 49: 375-377 
Plate I

Sevimli A. et al.: Oviduct cyst ... pp. 235-237

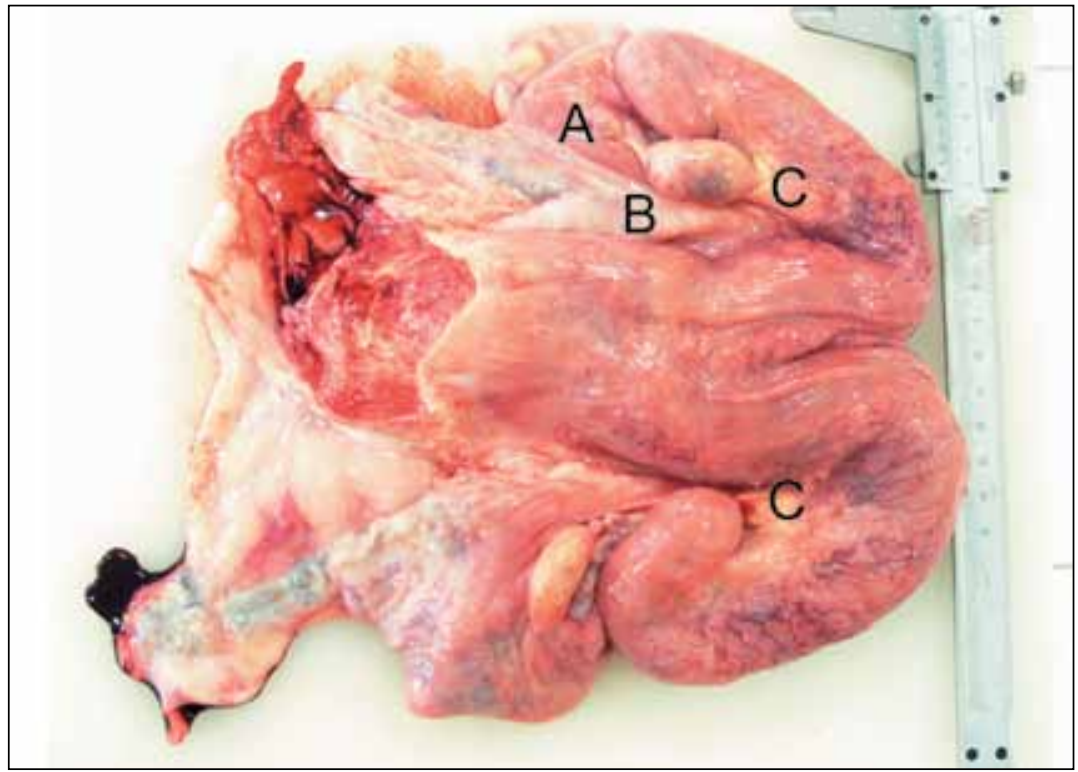

Fig. 1. Appearance of cysts in the uterus and oviduct in an Anatolian water buffalo. Cyst in oviduct (A), left ovarian follicle (B), cysts in uterine serosa (C)

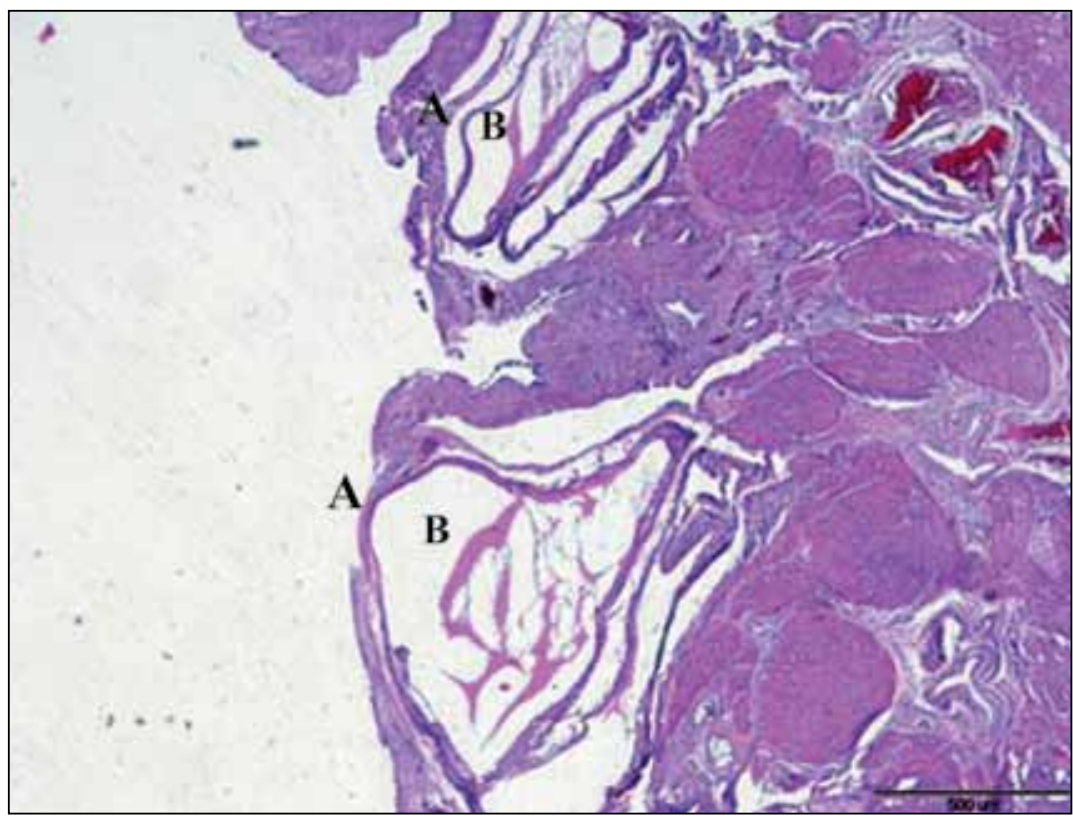

Fig. 2. Homogeneous amorphous structures in the uterine serosal inclusion cyst in an Anatolian water buffalo. Serosal cyst of the uterus (A), homogeneous amorphous structures pink in color (B), haematoxylin and eosin $\times 4$, bar: $500 \mu \mathrm{m}$ 
Plate II

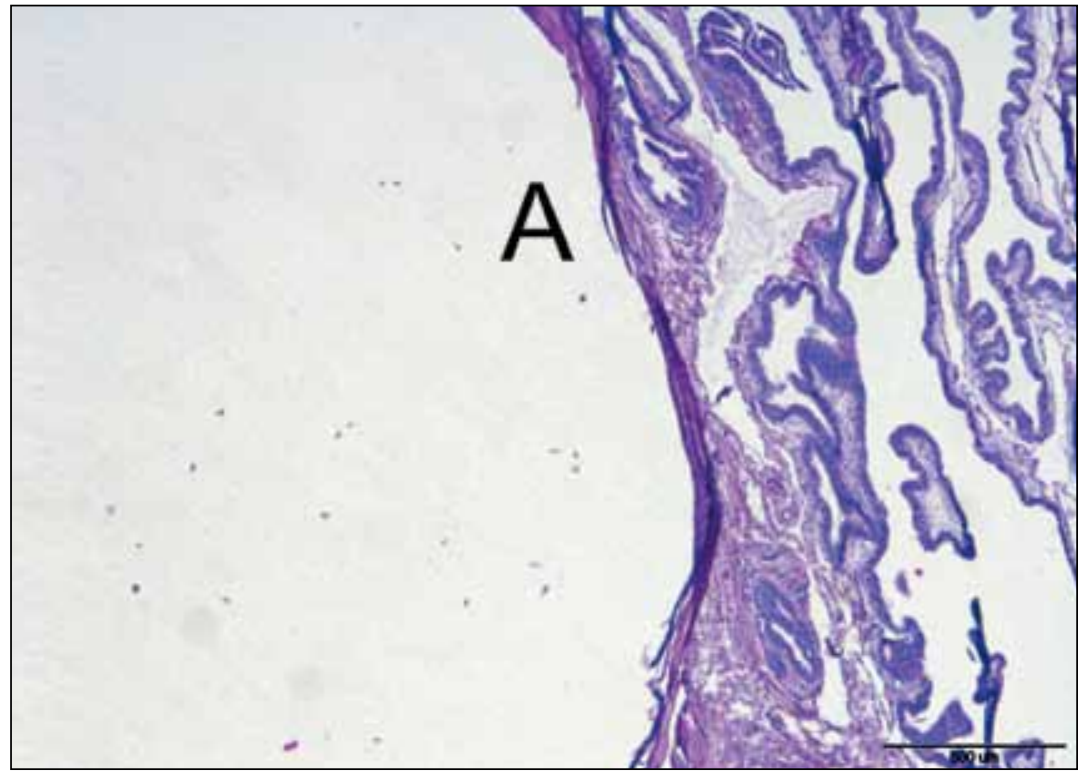

Fig. 3. Oviduct cyst in an Anatolian water buffalo. Lumen of oviduct cyst (A), haematoxylin and eosin $\times 4$, bar: $500 \mu \mathrm{m}$ 